\title{
Shared responsibility for post-Kyoto
}

\author{
A. Hoeltl ${ }^{1} \&$ R. Brandtweiner ${ }^{2}$ \\ ${ }^{I}$ Department for Management and Economics, \\ Danube University Krems, Austria \\ ${ }^{2}$ Department of Information Systems \& Operations, \\ Vienna University of Economics and Business, Austria
}

\begin{abstract}
The approach of the Kyoto Protocol of the United Nations Framework Convention on Climate Change (UNFCCC) is currently production-based only. This means that greenhouse gas (GHG) emissions are calculated and assigned on the basis of production. Exports and imports as well as international transportation and the potential for carbon leakage are disregarded in the current Kyoto mechanism. The mechanism is considered unfair by an increasing number of Parties of the UNFCCC. Consumption-based accounting (CBA) can possibly be an approach for rebuilding the Kyoto Protocol into a fairer one, accepted by developed as well as by developing countries. CBA moves the responsibility from producers to consumers. The study at hand is aimed at making a contribution to the question of a fair and efficient combination of the two approaches. It develops an indicator that shares the responsibility for emissions embodied in traded goods among producers and consumers.

Keywords: climate policy, post-Kyoto, shared responsibility, production-based accounting, consumption-based accounting, international trade, international transportation.
\end{abstract}

\section{Introduction}

The Parties of the UNFCCC (including US, China and further emerging and developing nations) agreed on holding the increase in global average temperature below $2{ }^{\circ} \mathrm{C}$ above pre-industrial levels. For that a reduction of $80 \%$ of global GHG emissions is needed by 2050. Yet the measures and burden-sharing for reaching this goal remain unclear. 
Developing countries have no quantified emission targets during the first Kyoto period (2008-2012), regardless of the fact of being involved in the Kyoto mechanism by the Clean Development Mechanism (CDM). This mechanism aims to stimulate sustainable development and emission reductions. Furthermore technology transfer to developing countries should be a positive spin-off effect.

The experience with CDM projects as well as the post-Kyoto negotiations show that developing countries have to become more involved in order to meet the $2^{\circ} \mathrm{C}$ goal. While developed countries are afraid of competitive disadvantages, developing countries refer to the historical responsibility of the developed countries for global warming. They insist on equality regarding the use of our atmosphere.

The study at hand discusses CBA as an alternative or extension to the production-based accounting (PBA) approach of the Kyoto Protocol. Advantages of CBA are, e.g. encouraging environmental comparative advantage, addressing carbon leakage or reducing the importance of emission commitments for developing countries.

\section{Consumption-based accounting}

A post-Kyoto mechanism should be a global agreement with legally binding emission caps to the majority of countries. The current Kyoto Protocol commits the majority of the developed countries as well as countries with economies in transition (Annex I countries). The UNFCCC approach for the Kyoto Protocol is production-based only, which means that GHG emissions are calculated and assigned on the basis of production. Exports and imports as well as international transportation and the potential for carbon leakage are disregarded in the Kyoto mechanism. For these and further reasons, this mechanism is regarded neither appropriate and nor enforceable for post-Kyoto.

Under the PBA approach, countries with a large share of exports are put to a disadvantage. According to the PBA approach China, for example, would need emission allowances for $5.5 \mathrm{GtCO}_{2}$ (level 2005), and $4.4 \mathrm{GtCO}_{2}$ under the CBA approach (Lin and Sun [1]). Bruckner et al. [2] find that internationally traded goods comprised $27 \%$ of the global energy-related $\mathrm{CO}_{2}$ emissions in 2005 . The OECD countries consume almost $30 \%$ more $\mathrm{CO}_{2}$ than they produce, whereas the G77 countries consume $23 \%$ less $\mathrm{CO}_{2}$ emissions than they emit by national production. The largest net importers in 2005 were the United States with 1,255 $\mathrm{Mt} \mathrm{CO}_{2}$, Japan with $380 \mathrm{Mt}$, France $175 \mathrm{Mt}$, Germany $257 \mathrm{Mt}$, and the UK with $232 \mathrm{Mt} \mathrm{CO}_{2}$. The largest net exporters were China, Russia and India with 990 $\mathrm{Mt}, 330 \mathrm{Mt}$ and $136 \mathrm{Mt} \mathrm{CO}_{2}$ respectively. The production-based emissions per capita in 2005 were $10.6 \mathrm{t}$ for the OECD countries and $2.7 \mathrm{t}$ for the G77 countries; the consumption-based emissions per capita $13.7 \mathrm{t}$ and $2.1 \mathrm{t}$ respectively. Based on this aggregated level the CBA would mean a shift of the responsibility of $\mathrm{CO}_{2}$ emissions to the OECD countries. Especially net exporters of $\mathrm{CO}_{2}$ emissions would perceive a mechanism on the basis of $\mathrm{CBA}$ as a fair alternative. 
Accordingly, CBA could be an adequate approach for rebuilding the Kyoto framework into a fair, more balanced one that is accepted by both developed as well as developing countries. CBA moves the responsibility from producers to consumers. The GHG emissions of the entire life-cycle of a product are allocated to the final consumer. The results of the recent UN climate change conferences as well as the scientific literature (e.g. Bastianoni et al. [3], Davis and Caldeira [4], Peters [5]) point out that a post-Kyoto mechanism has to introduce the CBA approach. It can on the one hand reflect the UNFCCC principle of "common but differentiated responsibility" and on the other hand encourage participation.

Advantages of the CBA approach are to encourage environmental comparative advantage, to address carbon leakage or reduce the importance of emission commitments for exporting developing countries. This raises the probability of developing countries participating in a global agreement. It is also advantageous that CBA includes transportation emissions. Beyond that, the consumers have the possibility to be aware of the GHG emissions of their consumer behavior. The incentive for consumers to demand low-carbon products will increase. Furthermore a more differentiated responsibility between countries is shown, and collaborations regarding technology transfers between importing and exporting countries are stimulated. As a consequence the Kyoto mechanism CDM would become more attractive and effective.

\subsection{Environmental comparative advantage}

From the global point of view the production for a specific good should be situated in the region where it generates the fewest $\mathrm{CO}_{2}$ emissions. Ecologically speaking it makes, for example, more sense to produce energy intensive goods in countries which use mainly renewable resources (Peters and Hertwich [6]). A mechanism including CBA can make the most of this environmental comparative advantage. Currently, only CDM makes it attractive for Annex I countries to invest in energy saving production in Non-Annex I countries, because they can gain Certified Emissions Reductions (CER). CBA will encourage emission abatement in foreign countries considerably.

\subsection{Carbon leakage}

Under the Kyoto Protocol countries with binding reduction targets have a huge incentive to switch energy intensive production to other countries on the basis of PBA. This particularly applies to countries with no binding emission caps. This effect is called carbon leakage. The country importing and consuming these products is not responsible for the emissions. Carbon leakage is a huge problem of PBA. It can be reduced significantly by implementing CBA.

There is merely a small database for carbon leakage. Peters and Hertwich [7] estimate the degree of carbon leakage from the Kyoto Protocol as $19 \%$ of the domestic $\mathrm{CO}_{2}$ emissions of the Annex I countries.

Carbon leakage was not a subject if all countries of the world are participating in a post-Kyoto mechanism with binding emission caps. However, introducing a CBA scheme also enables the reduction of carbon leakage. Developed countries 
would take a greater share of $\mathrm{CO}_{2}$ emissions under a CBA post-Kyoto mechanism. Emission commitments for developing countries would become less important. Thereby the willingness for participation in such a mechanism for these countries would increase.

\subsection{International trade}

According to Peters and Hertwich [7], in $200126 \%$ of global energy related $\mathrm{CO}_{2}$ emissions resulted from trade. For different countries the bandwidth ranges from $9 \%$ to $69 \%$ of domestic $\mathrm{CO}_{2}$ emissions. $\mathrm{CO}_{2}$ emissions of imported products range from $6 \%$ up to $200 \%$ of domestic $\mathrm{CO}_{2}$ emissions.

CBA encourages emission abatement in foreign countries due to a reallocation of imports (Peters and Hertwich [6]). CBA will provide incentives for exporting countries to use low-carbon technologies because of the interest of importing countries in low-carbon products; even in the case the exporting country, as a developing country, would have no binding emission targets. Under the current PBA there is just a marginal incentive for low-carbon technologies for exporting countries without emission targets.

Additionally, CBA creates stronger incentives for technology transfer; especially for CDM in connection with relocating the domestic production to a developing country. Hence the emissions embodied in the imports of the country enabling technology transfer can be reduced - along with the emissions reduction commitment of that country.

\subsection{International transportation}

International transportation is responsible for an estimated 7\% of global $\mathrm{CO}_{2}$ emissions according to the U.S. Environmental Protection Agency [8]. The Kyoto Protocol does not hold anybody responsible for the $\mathrm{CO}_{2}$ emissions of international transportation. Allocating emissions embodied in international transportation to the countries consuming the respective transported goods is conclusive and thus another argument in the favour of CBA.

\subsection{Measurement for carbon emissions}

The assessment technique used to calculate embodied carbon emissions is, as a basic requirement, an important issue for a fair allocation of emissions responsibility. Carbon emissions can be calculated at the point of production, as practiced under the current Kyoto Protocol. This is a relatively simple method, where the input of fuels is multiplied with the carbon emission factor of the specific fuel. The term "embodied emissions" considers the emissions from each stage of the production process to the final consumer goods. There are different assessment techniques for this approach, such as carbon footprint and life-cycle analysis. Kejun et al. [9] investigate different approaches and state the necessity of more research on this issue. Nevertheless, these approaches take a closer look at the entire supply chain as opposed to the current calculation method used under the Kyoto Protocol. At the same time they are much more complex 
regarding data collection and required statistics, and therefore more costintensive.

Steckel et al. [10] argue that, within a general trade model, switching from PBA to CBA has no influence on the welfare of countries. In their opinion mainly ethical reasons argue for CBA; however, one should prefer PBA due to lower transaction costs. In the case of grandfathering (past emissions determine the emission allowances allocation) $\mathrm{CBA}$ and PBA will lead to different results of distribution. Net exporters of GHG emissions would benefit from PBA. In a mechanism where historical emissions of a country reduce its emission allowances, net exporters of GHG emissions would benefit from CBA. Hence the accounting system can influence the allocation of emission allowances. Steckel et al. [10] argue that the willingness of countries to contribute towards a post-Kyoto mechanism depends more on the initial allocation scheme of emission allowances than on the accounting method.

The allocation of emissions allowances on the basis of PBA is simpler than on the basis of CBA. Several studies already investigated GHG flows of international trade and the relationship between the individual countries (e.g. Peters and Hertwich [7]), but a detailed, overall analysis is still missing. For analyzing carbon emissions embodied in imports and exports of a country, a topdown method using input-output analysis could be applied (Kejun et al. [9]). Serrano and Dietzenbacher [11] compare different approaches for evaluating the international emissions responsibility of an individual country. Due to limited data availability they propose a simple alternative on an aggregate level evaluating the emissions embodied in trade. Regarding the appropriate evaluation method for the proposed indicators, further research is required; also for the calculation approach concerning the emissions embodied in international transportation.

\section{Sharing the responsibility between producers and consumers}

The allocation of emissions allowances on the basis of PBA is not as complicated as allocating them on the basis of CBA. Several studies have already investigated GHG flows of international trade and the relationship between the individual countries (e.g. Peters and Hertwich [7]), but a detailed, overall analysis is still missing. Beside the advantage in allocating emissions allowances by PBA, this approach allows high transparency and is consistence with GDP. Because the responsibility of the producers is emphasized, they have a stronger incentive to use low-carbon technologies. Pure CBA would reduce the incentive for low-carbon technology for producers significantly. This is particularly true in $\mathrm{CO}_{2}$ exporting countries.

In order to take advantages of CBA as well as PBA, a post-Kyoto mechanism should combine these two approaches. Producers as well as consumers have an incentive to reduce GHG emissions of a specific product. Reducing these emissions under shared responsibility is in the interest of each member of the supply chain. Collaboration between producer and consumer to reach this target 
is encouraged. There is no incentive for collaboration in full producer or full consumer responsibility.

Bastianoni et al. [3] developed an indicator that adds the embodied $\mathrm{CO}_{2}$ emissions of the respective upstream parts of the supply chain to each part of the supply chain of a product. This means that emissions are counted twice or multiple times. The resulting emissions of each part of the supply chain are divided by the sum of all resulting emissions of the entire supply chain. Bastianoni et al. [3] provide the indicator CEA (carbon emission added), which determines the responsibility of each part of the supply chain. For example: A supply chain has three parts $\mathrm{A}, \mathrm{B}$ and $\mathrm{C}$. According to PBA the embodied emissions are 50 units for A, 30 units for B and 20 units for C. Under the CEA approach, A is responsible for 50 units, B for 80 units $(50+30)$ and $\mathrm{C}$ for 100 units $(50+30+20)$. The responsibilities divided by their sum $230(50+80+100)$ show us the final responsibility of each part of the supply chain: A with 22 units, $B$ with 35 units and $C$ as the last part of the supply chain with 43 units. By that indicator the responsibility increases within the supply chain; the consumer has the most responsibility.

Rodrigues et al. [12] propose an indicator of environmental responsibility that is unique for the required properties, like additivity, accountability for indirect effects for economic causality, monotony in direct environmental pressure, and symmetry in consumption and production. They emphasize the importance of the presentation of the data in a fair manner for the commitment of all parties to an international agreement. In their opinion the responsibility of a country should correspond to its contribution to total environmental pressure. Rodrigues et al. [12] describe the environmental responsibility of a country as a linear combination of the upstream environmental pressure of the final demand and of the downstream environmental pressure of the primary inputs of this country. They show that the environmental responsibility is the arithmetic average of the environmental pressure of final demand and primary inputs.

Lenzen et al. [13] focus on the problem of double-counting by adding producer's footprint to the footprint of another producer, or to consumer or population footprints. For this reason they discuss a method of delineating the supply chains, and propose an indicator which considers sector-specific fractions of upstream embodied emissions. This indicator allocates the responsibility according to added value. The sum of all upstream embodied emissions of one sector is identified as the producer responsibility. The part of the upstream embodied emissions reaching final demand is identified as the consumer responsibility.

\section{$4 \quad E R$ indicator}

The authors propose an indicator based on the experiences under the Kyoto Protocol and on the scientific literature. The idea was to develop an indicator that, on the one hand, can be implemented in the current scheme and, on the other hand, increases the willingness of participation of developed as well as of developing countries. The proposed ER (Emissions Responsibility) indicator 
combines the advantages of a consumption-based principle and of a productionbased principle. The basis is PBA, which means that the basis for calculation are the emissions arising from production. But the responsibility for internationally traded goods is shared between producers and consumers.

The ER indicator shows the responsibility of a country for its carbon emissions by the emissions embodied in the domestic production minus a fraction $\alpha$ of the emissions embodied in the exports of the country and plus a fraction $\alpha$ of the emissions embodied in its imports:

$$
E R=E E P-\alpha E E E+\alpha E E I
$$

ER ... emissions responsibility

EEP ... emissions embodied in domestic production

EEE ... emissions embodied in ex ports

EEI ... emissions embodied in imports

EEC ... emissions embodied in consumption

Fraction $\alpha$ of the emissions embodied in exports of country $\mathrm{A}$ is allocated to the importing country $\mathrm{B}$; hence country $\mathrm{A}$, as the producing country, is responsible for the fraction $1-\alpha$ of its exports. For $0<\alpha<1$ the authors propose 0.5 , which means that half of the emissions embodied in traded goods are allocated to the producing country and half to the consuming country. Table 1 demonstrates the impact of the proposed $E R$ indicator on the carbon emissions responsibility of individual countries.

Table 1: Impact of the $E R$ indicator on the individual country's carbon responsibility, $\alpha=0.5$.

\begin{tabular}{|c|c|c|c|}
\hline & $\mathrm{A}$ & $\mathrm{B}$ & $\mathrm{C}$ \\
\hline$E E P$ & 120 & 80 & 40 \\
\hline$E E E$ & 60 & 40 & 20 \\
\hline$E E I$ & 20 & 40 & 60 \\
\hline$E E C$ & 80 & 80 & 80 \\
\hline$E R=E E P-0.5 E E E+0.5 E E I$ & 100 & 80 & 60 \\
\hline
\end{tabular}

Country A has a high production level as well as a high export quota. In comparison country $\mathrm{C}$ has a much lower production level but a much higher import quota. The consumption of country $\mathrm{C}$ embodies the same carbon emissions like the consumption of country A, but the carbon emissions responsibility of country $\mathrm{A}$ would be much higher than the responsibility of country $\mathrm{C}$ because of the producer responsibility as an exporting country. Country B with balanced carbon trade is responsible for the emissions that are embodied in its consumption. In sharing the responsibility for traded goods, countries switching the production to other countries are better off. 
This could be acceptable if one argued that countries with high exports have the corresponding advantages (added value, jobs) on the one hand, and better possibilities for reducing emissions embodied in production by using low-carbon technologies on the other hand.

In Table 2 the authors demonstrate the $E R$ indicator with shifting the carbon emissions responsibility to the importing country by determining $\alpha$ as 0.75 of the embodied emissions. Thereby the producing country keeps a lower carbon emissions responsibility of 0.25 for its exports.

Table 2: Impact of the $E R$ indicator on the individual country's carbon responsibility, $\alpha=0.75$.

\begin{tabular}{|c|c|c|c|}
\hline & $\mathrm{A}$ & $\mathrm{B}$ & $\mathrm{C}$ \\
\hline$E E P$ & 120 & 80 & 40 \\
\hline$E E E$ & 60 & 40 & 20 \\
\hline$E E I$ & 20 & 40 & 60 \\
\hline$E E C$ & 80 & 80 & 80 \\
\hline$E R=E E P-0.75 E E E+0.75 E E I$ & 90 & 80 & 70 \\
\hline
\end{tabular}

Comparing the emissions responsibility in table 1 and 2 it is obviously that with an increasing value for ${ }_{\text {the }}$ responsibility shifts more to the consumer side. The responsibility of the exporting country A decreases from 100 to 90, and the emissions responsibility of the importing country $\mathrm{C}$ increases from 60 to 70 .

\section{$5 \quad$ ERIT indicator}

As the $E R$ indicator does not include carbon emissions embodied in international transportation, the indicator can be expanded correspondingly. Under the assumption that carbon emissions embodied in international transportation can be allocated to the imports, it is proposed to add the responsibility for these emissions to the consumers. On the one hand the consumer responsibility is strengthened and on the other hand an importing country is able to influence the mode of transportation. Cadarso et al. [14] indicate the allocation of emissions embodied in international transportation as Broad Consumer Responsibility.

The ERIT (Emissions Responsibility including emissions embodied in International Transportation) indicator shows the responsibility of a country for its carbon emissions by the emissions embodied in the domestic production minus a fraction $\alpha$ of the emissions embodied in the exports of the country, plus a fraction $\alpha$ of the emissions embodied in its imports and plus the emissions embodied in international transportation associated with imports:

$$
E R I T=E E P-\alpha E E E+\alpha E E I+E E I T
$$

EEIT ... emissions embodied in international transportation of imports ERIT ... emissions responsibility including emissions embodied in international transportation 
Table 3: Impact of the ERIT indicator on the individual country's carbon responsibility, $\alpha=0.75$.

\begin{tabular}{|c|c|c|c|}
\hline & A & B & C \\
\hline$E E P$ & 120 & 80 & 40 \\
\hline$E E E$ & 60 & 40 & 20 \\
\hline$E E I$ & 20 & 40 & 60 \\
\hline$E E C$ & 80 & 80 & 80 \\
\hline$E E I T$ & 5 & 10 & 15 \\
\hline$E R I T=E E P-0.75 E E E+0.75 E E I+E E I T$ & $9^{5}$ & 90 & 85 \\
\hline
\end{tabular}

Including emissions embodied in international transportation to our indicator and allocating them to the consumers means a more balanced carbon emissions responsibility between producers and consumers.

\section{Conclusion}

The authors are of the opinion that the Kyoto Protocol was and still is a milestone in global environmental policy. It makes sense to look for small but effective changes to this protocol instead of looking for a completely new scheme. CBA could be this effective change for post-Kyoto, helping to increase the acceptance of a contribution among both developing and developed countries.

The proposed ER and ERIT indicators calculate the emissions on the basis of the much simpler PBA approach, but share the responsibility for traded goods between producers and consumers. Thereby the authors combine the advantages of the PBA and CBA approach. Emissions embodied in international transportation are allocated to the consuming country.

Further research is required regarding the appropriate measurement for carbon emissions; additionally regarding the level of $\alpha$, as the responsibility for emissions embodied in imports, and how the historical responsibility of the developed countries could be integrated in the proposed indicators.

The ER and ERIT indicators indentify the emissions responsibility allocated to the different countries. In a further step a proposal for an emission allowances scheme is required, which determines the progress of the country-related carbon emission allowances until 2050, taking into account that the increase in global average temperature has to be hold below $2^{\circ} \mathrm{C}$ above pre-industrial levels.

\section{References}

[1] Lin, B. \& Sun, C., Evaluating carbon dioxide emissions in international trade of China. Energy Policy, 38, pp. 613-621, 2010.

[2] Bruckner, M., Polzin, Ch. \& Giljum, S., Counting $\mathrm{CO}_{2}$ emissions in a globalised world. DIE Research Project "Development Policy: Questions for the Future”, Bonn, 2010. 
[3] Bastianoni, S., Pulselli, F.M. \& Tiezzi, E., The problem of assigning responsibility for greenhouse gas emissions. Ecological Economics, 49, pp. 253-257, 2004.

[4] Davis, S.J. \& Caldeira, K., Consumption-based accounting of $\mathrm{CO}_{2}$ emissions. Proceedings of the National Academy of Sciences of the United States of America, vol.107, no.12, pp. 5687-5692, 2010. http://www.pnas.org/content/107/12/5687.full.pdf+html

[5] Peters, G.P., From production-based to consumption-based national emission inventories. Ecological Economics, 65, pp. 13-23, 2008.

[6] Peters, G.P. \& Hertwich, E.G., Post-Kyoto greenhouse gas inventories: production versus consumption. Climate Change, 86, pp. 51-66, 2008.

[7] Peters, G.P. \& Hertwich, E.G., Trade and the environment: implications for climate change policy. Ninth biennial conference of the international society for ecological economics on ecological sustainability and human well-being. New Dehli, India, 2006.

[8] U.S. Environmental Protection Agency, Trade, Transportation and Environment. http://www.epa.gov/oia/trade/transport.html

[9] Kejun, J., Cosbey, A. \& Murphy, D., Embodied Carbon in Traded Goods. Trade and Climate Change Seminar. Copenhagen, Denmark, International Institute for Sustainable Development (IISD), June 18-20, 2008.

[10] Steckel, J.Ch., Kalkuhl, M. \& Marschinski, R., Should carbon-exporting countries strive for consumption-based accounting in a global cap-and-trade regime? PIK Working Paper, Mar 2010.

[11] Serrano, M. \& Dietzenbacher, E., Responsibility and trade emission balances: An evaluation of approaches. Ecological Economics, 69, pp. 2224-2232, 2010.

[12] Rodrigues, J., Domingos, T., Giljum, S. \& Schneider, F., Designing an indicator of environmental responsibility. Ecological Economics, 59, pp. 256-266, 2006.

[13] Lenzen, M., Murray, J., Sack, F. \& Wiedmann, T., Shared producer and consumer responsibility - Theory and practice. Ecological Economics, 61, pp. 27-42, 2007.

[14] Cadarso, M.A., López, L.A., Gómez, N. \& Tobarra, M.A., $\mathrm{CO}_{2}$ emissions of international freight transport and offshoring: Measurement and allocation. Ecological Economics, 69, pp. 1682-1894, 2010. 